\title{
Connection Beyond Words: Establishing Emotional Communication with Autistic Children
}

Yangyi Tai ${ }^{1}$ and Jihua Yang ${ }^{2 *}$

${ }^{1}$ University College London, London, United Kingdom

${ }^{2}$ Department of Oncology, Fifth Medical Center of PLA General Hospital, Middle Street of 4th West Ring Road, Beijing, China

*Corresponding author: J ihua Yang, Department of Oncology, Fifth Medical Center of PLA General Hospital, Middle Street of 4th West Ring Road, Beijing, 100039, China

Received: J une 21, 2021; Accepted: J uly 13, 2021; Published: July 20, 2021

\begin{abstract}
To help autistic children promote Social Competence (SC) and connect to other people, the study designed a therapy toy that can react emotional response and provide haptic communication, in a comfortable and engaging way. Five children with autism were invited to play with the device focusing on the evaluation of interactions and behaviors. The results show significant relief of autism severity and improvements on the willing of expression.
\end{abstract}

Keywords: Autism; Children; Mental health; Psychology; Haptic therapy

\section{Introduction}

Autism Spectrum Conditions are neuro-psychological disorders commonly apparent around 3 years old [1]. Children with autism feel difficult to process sensory information and to interact with external stimulation [2]. It is characterized by three symptoms: 1) repetitive and obsessive behaviors; 2) atypical communication skills; 3) abnormalities in social relationships. Current explanation of autism is disease hereditary and there is no cure for the condition [3]. The overall intelligence degrees of autistic group vary greatly. Although the impairments in social and communication may stay a lifetime, the potential of education and therapy to activate children with autism is hard to ignore. Some people diagnosed with Asperger Syndrome have the ability to take care of their life independently and get successful career when they grow up [4].

The existing therapeutic methods for autism include behavior therapy, game therapy, art therapy, music therapy and so forth [5]. The therapies currently in used is more about "learned routine" instead of "spontaneous". Spontaneity allows autistic children to present themselves and integrate in social activities, in turn, achieve the development of social inclusion [6]. Therapists need play with autistic children indirectly because of the problem of fearing people. For this reason, it is required to have an object between therapists and children no matter which way we use. Limited SC is the major impairment that prevent the communication of autism. Research does demonstrate that game therapy could help autistic children acquire SC and facilitate imagination in the long term [7]. The alternative strategy for autism could be non-verbal communication like touch-based interfaces.

However, limited study has focused on the exploration of sensory products for autistic children to calm and relax. Sometimes, therapists and parents need modify the toys by themselves in order to adapt to their needs [8]. The idea is to develop a novel therapy to increase vocalizing and improve the quality of family life. This study aimed to design a portable and accessible toy for children to interact and connect to the outside world with safety. The challenge is to attract their attention and increase their performance of concentration. To address the social aspect of the design, the toy should be able to encourage children with autism to proactively integrate in a group and to open up to the surroundings.

\section{Literature Review}

\section{Triadic interaction}

Triadic relation is composed of a child, a robot, and another participant could be a child, a parent, or a therapist. Research has claimed the effect of using objects to elicit conversations between autistic children and the others [9]. Children with autism are attracted by mechanical objects such as toys and robots and emerge novel social interactions during the observation. These children treat toys as mediators to convey information which results in promoting interactions. An independent study shows the presence of robots encouraged the children to directly ask help from therapists [10]. On one hand, it demonstrated that triadic interaction is the essential pivot for autism to achieve or transfer communication. On the other hand, it provided evidence that game therapy could generate improvements in SC.

\section{Tangible user interface}

Children interact with objects reflect their perception of how they position themselves in the world [11]. Autistic children appear delay on the development of functional and social respects in connection with objects. They tend to explore smell, taste and touch in a repetitive way without function needs [12]. Understanding the relationship between autistic children and objects could assist the development of interventions on game therapy to improve SC. Tangible User Interface (TUI) is more intuitive and entertaining for children. It allows sharing space between companions which increases the observations of behavior and enable the possibility of interacting with autistic children. Compared with LEGO intervention, playing with TUI could reduce the solitary activities and facilitate collaborative and associative play sequences [13]. The results of experimental studies showed the usability and emotions of touch-based interfaces were more positive than remote interfaces $[14,15]$.

\section{Non-humanoid appearance}

The appearances of object influence the efficiency of therapy in clinic. Children with autism generally withdraw and avoid interactions 
with human forms. The abstract and cartoonish appearances could appeal them especially when they are introduced to the toys at the first time [16]. Pet-like objects make them engage and elicit emotional connections within the games. This observation is consistent with the general understanding of autistic children gravitate toward repeatable and mechanical behaviors. Researchers advocate the approach of designing simple interactions with appropriate appearances to minimize the frequency of distractions [17]. In fact, non-humanoid robots are much more affordable than the human forms. Children could start therapy with the simple object and switch to the realistic one once they get comfortable. This way, they could wean off the mechanical mediator and interact with people naturally.

\section{Haptic therapy}

Recent research discusses that mental disorders can be significantly affected by the touch sensations [18]. The Wilbarger Protocol and Therapeutic holding are revealed as sensory integrations to effectively treat depressive and anxiety disorders. Brushing, joint compression and weight are three types of touch practices presented by The Wilbarger Protocol [19]. The psychotherapeutic outcomes are enhanced when message is involved in regimen [20]. Therapeutic holding is applied as an alternative way to restrain aggressive children in America. Children feel less punitive because of the reducing of mechanical restraints [21]. The meaning of haptic stimulation is addressed as an intervention for autistic children to distract attention, manage pain and avoid panic attack [22].

Rather than face to face dialogue, children prefer to revolve communication around play [23]. In particular, autism have trouble with verbalism because of the limited conversation skills. A research mentioned the meaning of touch related to younger children, it could provide the feeling of connection when children are separated with their parents [24]. Interpersonal touch could promote affective response and emotional wellbeing to address the meaning of nonverbal communication. Existing product such as Frebble [25] are proposed to allow people to hold hands remotely with physical and emotional connections.

\section{Research}

\section{Interview and observation}

In order to gather detailed user requirements that could help autistic children evoke the desire of expression and leave stressful situation, we conducted an investigation with the autistic children below the age of 7 around one week. By visiting a special education school in China, we observed potential factors that may affect the interactions between autistic children and toys. Additionally, we prepared semi-structed interviews to ask parents and therapists about children's favorite objects and activities during the process.

From the observation, we found therapists use toys to help children calm down in the three situations: 1) when they are not allowed to do something; 2) when they are interrupted by something 3) when their requirements are denied. The children are easy to get overwhelmed by sensatory stimulation. Since their communication skills are limited, the key of guiding comfortable conservation is to provide the variation from simple to complex interactions. They are interested about ball-size moving toys. Colors and lights could facilitate their emotional connection with the objects. We tested

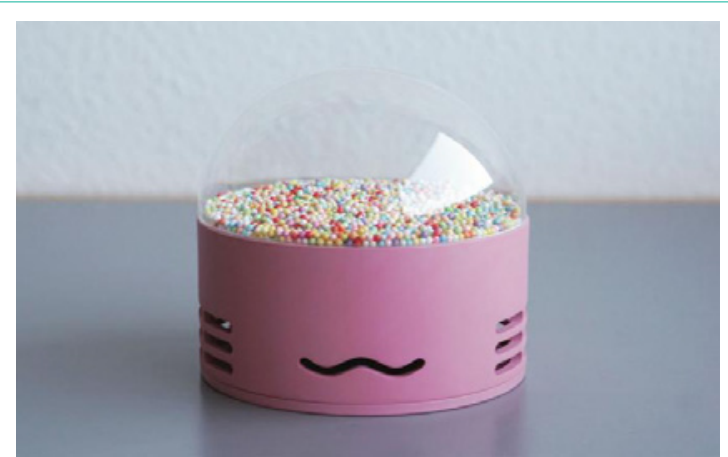

Figure 1: Mockup of "we".

three types of vibration including heartbeat, phone haptics and breath frequency. The results showed they could only perceive simple patterns from strong vibration to soft vibration instead of distinguishing various forms.

\section{Established requirement}

Based on the findings, a list of design needs was summarized:

- The size should be small and lightweight for children to play around.

- The shape should be rounded to attract attention and to keep safety.

- The colors of the light should vary based on the emotion in order to elicit expression and maintain calm.

- The interactions should be simple and easy to understand.

- The patterns of haptic could be strong vibration, soft vibration, and no vibration.

- The signal should be motion-based to visually engage children.

\section{"we" Prototype}

"we' (Figure 1) is a toy designed to assist autistic children to communicate and socialize with family and surroundings. The goal is to engage them in multisensory interactions while simultaneously tracking their emotions. "we" uses sensors to detect and react to children's behaviors in order to help them explore emotional cognition and SC. For example, it will turn red light if a child hurts it or throws it away. Parents and therapists could use the toy to guide children through different tasks and activities. The device could be paired remotely to send haptic communication, when a child touch the screen, the other device will vibrate with the floating balls. The patterns of vibration determined by the strength of touch.

\section{Method}

\section{Design}

The study was approved by the UCL Departmental Ethics Committee. It used a between-subjects design. The independent variables were emotion and touch. The dependent variables were color and vibration. The Wizard of $\mathrm{Oz}$ testing has been integrated into the experiments. Sensors sent real-time signals to the toy after detecting children's behaviors. Since there was no control group during the 


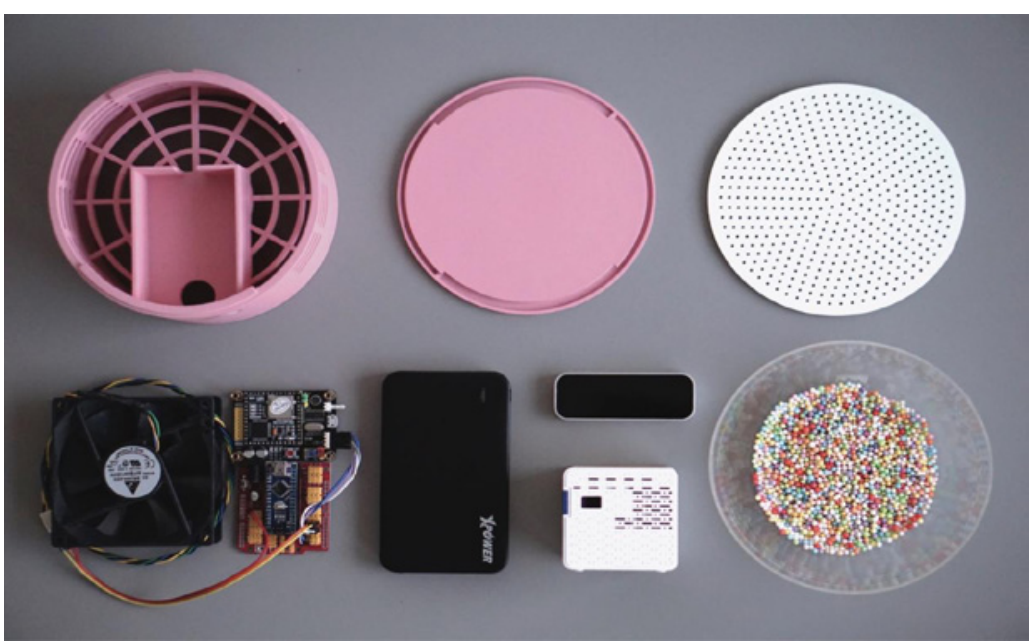

Figure 2: Design of the mockup.
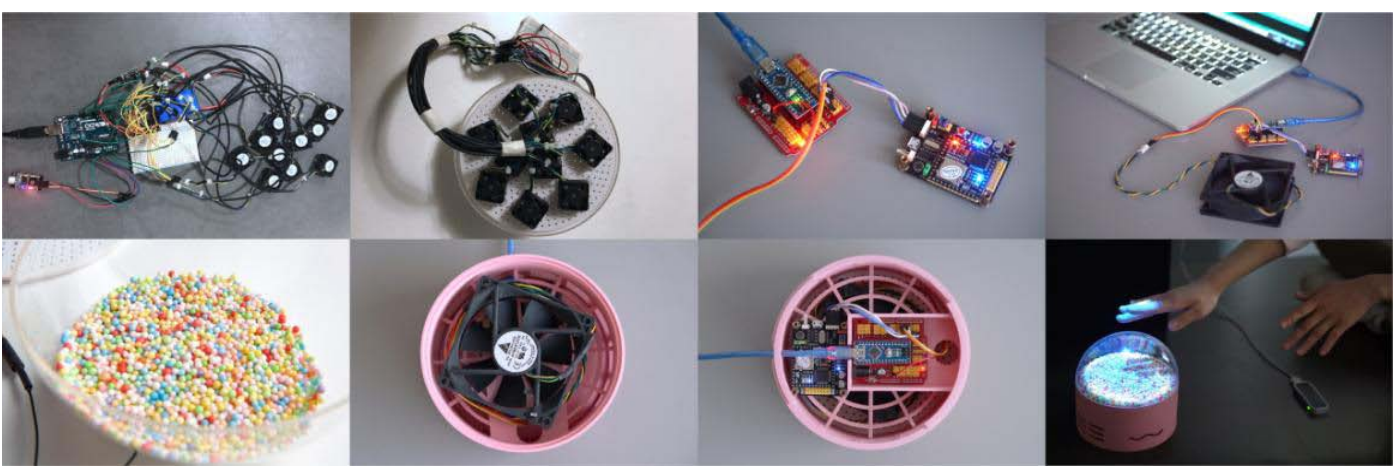

Figure 3: Electronic prototype.

evaluation, our focus was on comparing each child's performances with his or her previous situation based on the GARS Questionnaire.

\section{Participants}

5 autistic children ( 3 female) and 5 parents have been recruited from the same Chinese special education school. Children are aged between 3 and 7 years (mean age $=5$ ). Three children were Pervasive Developmental Disorders and the remaining two were Autistic Disorders with different degrees of communication skill. The experiments have two phases and lasted 5 days. Each child was observed around 3 hours (total 15 hours). In-depth interviews were conducted with their parents to collect extra information and feedbacks. Informed consent forms have been signed by their guardians since autistic children are not capable of civil conduct.

\section{Materials}

Electronic prototype consists of Arduino, vibration sensor, speech recognizer, Leap Motion, and mini projector (Figure 2). The mini projector was used to display the variations of light. Vibration sensor and Leap Motion were designed to transfer haptic communication. GARS Questionnaire was applied to collect data for the measurement of affective interactions (Figure 3).

\section{Procedure}

Children were accompanied by the therapist and the experimenter that sat at the back of the room. Their parents stayed in the next room.
The therapist introduced how to interact with the toy at the beginning and was allowed to guide children while they were playing. Before the experiment, both parents and the therapist were trained by the experimenter and assigned time to familiarize themselves.

The experiment was composed of two phases:

- Phase 1: Children were allowed to play with the toy by themselves around 20 minutes. After that, they were asked to complete daily tasks depending on the situation such as washing hand. If they performed well, the device would turn green light otherwise it would turn red light. The toy would display different colors of light to express their emotion while interacting with children.

- $\quad$ Phase 2: Children were allowed to emotionally connect to their parents though the haptic communication. They could send strong or light vibrations based on the strength of touch. Children did not know their parents stay at the other room until the end of the experiments.

\section{Results}

The results of GARS showed the reduction associated with autism severity of five children from Pre-test, Phase 1 and Phase 2 (Figure 4). It revealed that children with autism enjoy interacting with the toy and are interested with the haptic communication. Detailed evaluation of the GARS questionnaire presented the improvement 


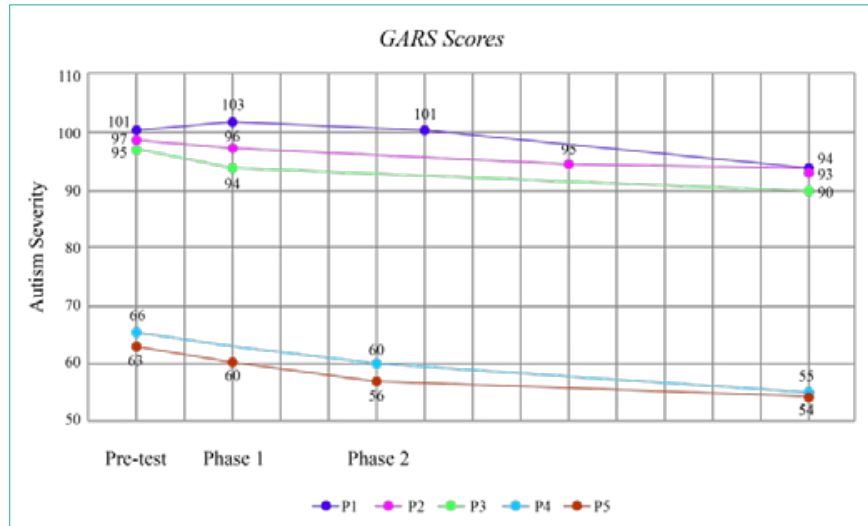

Figure 4: GARS scores of five autistic children.

of P2 and P5 in regards to SC. P1 felt anxious to play with the new toy at first and started to engage after Phase 1. Overall GARS scores keep stable impact on children during Phase 2. All children feel comfortable to communicate with their parents though vibrations and keep sending signals after familiarization.

\section{Discussion}

\section{Contribution}

"we" allows autistic children to communicate with their parents and peers when they are not physically together. It stimulates children's willing to express themselves and practice SC with the novel interactions. It helps them build up self-esteem every time when they complete the tasks by reinforcing affective response. The haptic language allows them to concentrate and to stay comfortable. We believe it is a valuable contribution, as children with autism currently do not have effective tools to transfer emotional connections.

\section{Limitation and future work}

The small sample size limits the validation of the scientific and statistical analysis. To further assess the influence of "we" on the development of children, it is necessary to conduct a detailed longterm evaluation to observe their reactions both at home and school. The current function of "we" is mainly focusing on initiating simple communication. At this point, the behavior therapy doesn't play a significant role because the difficulties of conveying complex information and tasks. The next step is to explore multiple levels of educational meaning with larger range of imitative interactions starting with simple to sophisticated situations. In this way help children promote their imagination and break the repetitive patterns over times.

\section{References}

1. Dautenhahn K, Billard A. Games children with autism can play with robota a humanoid robotic doll. Universal Access and Assistive Technology. 2000; 179-190.

2. Misal D. What Is The Difference Between A Chatbot And Virtual Assistant. Analytics India Magazine. 2009.

3. Bowman OJ. Sensory Integration: Theory and Practice. American Journal of Occupational Therapy.

4. Lord C, Leventhal BL, Cook EH. Quantifying the Phenotype in Autism Spectrum Disorders. American Journal of Medical Genetics. 2002.
5. Baron-Cohen S, Leslie AM, Frith U. Does the autistic child have a "theory of mind" ? Cognition. 1985; 21: 37-46.

6. Williams E, Reddy V, Costall A. Taking a closer look at functional play in children with autism. Journal of Autism and Developmental Disorders. 2001.

7. Hendrix K, Van Herk R, Verhaegh J, Markopoulos P. Increasing children's social competence through games, an exploratory study. Proceedings of the 8th International Conference on Interaction Design and Children - IDC '09. 2009.

8. Simpson CG, Lynch SA. Adapting and Modifying Toys for Children with Special Needs. ERIC. 2003.

9. Stanton CM, Kahn PH, Severson RL, Ruckert JH, Gill BT. Robotic animals might aid in the social development of children with autism. Proceedings of the 3rd International Conference on Human Robot Interaction - HRI '08. 2008.

10. Robins B, Dautenhahn K. The Role of the Experimenter in HRI Research A Case Study Evaluation of Children with Autism Interacting with a Robotic Toy. ROMAN 2006 - The 15th IEEE International Symposium on Robot and Human Interactive Communication. 2006.

11. Williams E. A comparative review of early forms of object-directed play and parent-infant play in typical infants and young children with autism. Autism. 2003; 7: 361-374.

12. Rowland CM, Schweigert PD. Object lessons: How children with autism spectrum disorders use objects to interact with the physical and social environments. Research in Autism Spectrum Disorders. 2009; 3: 517-527.

13. Farr W, Yuill N, Raffle $H$. Social benefits of a tangible user interface for children with autistic spectrum conditions. Autism. 2000; 14: 237-252.

14. Kim N, Han J, Ju W. Is a robot better than video for initiating remote social connections among children? Proceedings of the 2014 ACM/IEEE International Conference on Human-robot Interaction. 2014.

15. Woo J, Suk H, Lee HJ, Lim Y. Touch or remote. CHI '13 Extended Abstracts on Human Factors in Computing Systems on - CHI EA '13. 2013.

16. Dautenhahn K, Werry I. Towards interactive robots in autism therapy. Pragmatics and Cognition. 2014; 12: 1-35.

17. Kozima $\mathrm{H}$, Nakagaw $\mathrm{C}$. Interactive robots as facilitators of CHILDRENS social development. Mobile Robots: Towards New Applications. 2006.

18. Bundy AC, Lane S, Murray EA, Fisher AG. Sensory integration: Theory and practice. 2002.

19. Champagne T, Stromberg N. Sensory approaches in inpatient psychiatric settings: Innovative alternatives to seclusion \&amp; restraint. Journal of Psychosocial Nursing and Mental Health Services. 2004; 42: 34-44.

20. Collinge W, Wentworth R, Sabo S. Integrating Complementary Therapies into Community Mental Health Practice: An Exploration. The Journal of Alternative and Complementary Medicine. 2005; 11: 569-574.

21. Berrios CD, Jacobowitz WH. Therapeutic holding: Outcomes of a pilot study Journal of Psychosocial Nursing and Mental Health Services. 1998; 36: 1418.

22. Vaucelle $\mathrm{C}$, Abbas $\mathrm{Y}$. Touch. $\mathrm{CHI}$ '07 Extended Abstracts on Human Factors in Computing Systems - CHI '07. 2007.

23. Raffle H, Spasojevic M, Ballagas R, Revelle G, Horii H, Follmer S, et al Family story play. Proceedings of the 28th International Conference on Human Factors in Computing Systems - CHI '10. 2010.

24. Gallace A, Spence C. The science of interpersonal touch: An overview. Neuroscience Biobehavioral Reviews. 2000; 34: 246-259.

25. Massung E, Dickins S, Torbett J, Holmes J, Cater K, Bates V. Intouch tactile tales. Proceedings of the 33rd Annual ACM Conference Extended Abstracts on Human Factors in Computing Systems. 2010. 